\title{
Protective effect of Letinous edodes foot peptides against ethanol-induced liver injury in L02 cells
}

\author{
LIN MA ${ }^{1,2}$, CHUN-YAN HUO ${ }^{1}$, XIAO-YU ZHANG ${ }^{1}$, CHEN-QIANG QIN $^{1}$, DI-FENG REN ${ }^{1}$ and JUN LU ${ }^{2}$ \\ ${ }^{1}$ Beijing Key Laboratory of Forest Food Processing and Safety, College of Biological Sciences and Biotechnology, \\ Beijing Forestry University, Beijing 100083; ${ }^{2}$ Beijing Engineering Research Center of Protein and Functional Peptides, \\ China National Research Institute of Food and Fermentation Industries, Beijing 100015, P.R. China
}

Received December 6, 2017; Accepted May 9, 2018

DOI: $10.3892 / \mathrm{mmr} .2018 .9093$

\begin{abstract}
The aim of the present study was to evaluate the protective effect and mechanism of Letinous edodes foot peptides on ethanol-induced L02 cells. A cell model of ethanol-induced damage was established in vitro to study the effects of the Letinous edodes foot peptides on human L02 hepatocytes. The expression and activity of superoxide dismutase (SOD), malondialdehyde (MDA), aspartate aminotransferase (AST), alanine aminotransferase (ALT), alcohol dehydrogenase (ADH) and acetaldehyde dehydrogenase $(\mathrm{ALDH})$, following treatment were examined to determine the anti-alcoholism and hepatoprotective functions of Letinous edodes foot peptides. Taking Letinous edodes foot peptides prior to ethanol exposure was more beneficial, which significantly increased SOD activity and the mRNA expression of ADH and ALDH suppressed by ethanol. In addition, the intracellular MDA content, and AST and ALT activity decreased in ethanol-induced L02 cells pretreated with the peptides, when compared with the control. Furthermore, Letinous edodes foot peptides inhibited the ethanol-induced activation of the proinflammatory cytokines, interleukin- 6 and tumor necrosis factor- $\alpha$, and promoted the metabolic regulation factors, AMP-activated protein kinase- $\alpha 2$ and peroxisome proliferator-activated receptor- $\alpha$.
\end{abstract}

Correspondence to: Professor Di-Feng Ren, Beijing Key Laboratory of Forest Food Processing and Safety, College of Biological Sciences and Biotechnology, Beijing Forestry University, 35 Qinghua East Road, Haidian, Beijing 100083, P.R. China

E-mail: rendifeng@bjfu.edu.cn

Professor Jun Lu, Beijing Engineering Research Center of Protein and Functional Peptides, China National Research Institute of Food and Fermentation Industries, Building 6, Courtyard 24, Jiuxianqiao Middle Road, Chaoyang, Beijing 100015, P.R. China

E-mail: johnljsmith@163.com

Key words: Letinous edodes foot peptide, ethanol-induced liver injury, antioxidation, anti- inflammatory effect, L02 cell

\section{Introduction}

Alcoholic liver disease (ALD), which is mainly caused by excessive alcohol drinking, endangers human health worldwide (1). Individuals with ALD that progress to advanced disease stages with liver fibrosis and cirrhosis have increased risk of complications such as portal hypertension, liver cancer and liver failure (2).

The liver contains diverse enzymatic systems to metabolize ethanol associated with many important metabolic functions (3). Under normal circumstances, most of the ethanol in the body could be catalyzed by alcohol dehydrogenase (ADH) and acetaldehyde dehydrogenase (ALDH) (4). Therefore, the bioactivity for dealing with ethanol can be reflected by the activation rate of ADH and ALDH. Tumor necrosis factor $\alpha$ (TNF- $\alpha$ ), one of the most important proinflammatory factors, is produced and secreted by hepatic parenchymal cells and Kupffer cells during the process of alcoholic liver injury $(5,6)$. Moreover, interleukin 6 (IL-6) can induce significant injuries in Kupffer cells mainly by reduction in ADH and ALDH activities owing to the long-term excessive ethanol consumption, causing aggravating damage to liver cells by ethanol and acetaldehyde (4). Furthermore, reduction in liver cell function results in decreased expression of the intracellular response factors, AMP-activated protein kinase (AMPK)- $\alpha 2$ and peroxisome proliferator-activated receptor (PPAR)- $\alpha$ (7), and enhanced expression of the inflammatory factors, TNF- $\alpha$ and IL-6, leading to liver cell injury.

Edible mushrooms, which are rich in proteins as well as trace minerals, and low in fat (8), have long been used in folk medicines and health foods. Lentinus edodes, also named Xianggu in Chinese and Shiitake in Japanese, is one of the most widely used edible mushrooms in the global market because of its flavor and nutritional profile (9). Research on effective components of Lentinus edodes has revealed that they have diverse beneficial effects, including immune regulation, anti-tumor, anti-aging, liver protection and resistance to respiratory infections (10-12). Mycelia zinc polysaccharides of Lentinus edodes have been found to upregulate the anti-aging activity of total antioxidant capacity, GSH peroxide and superoxide dismutase (SOD), and downregulate the malondialdehyde (MDA) content in vivo (13). Other compounds such as polyphenols and crude polysaccharides in Lentinus edodes 
have also been reported to exhibit potent antioxidative bioactivities (14-17). Taking advantages of the high content of protein and balanced amino acid compositions, we previously obtained enzymatic hydrolyzed peptides from Letinous edodes umbrellas and feet, and found that Letinous edodes foot peptides possessed strong activation abilities on ADH and ALDH activities in vitro $(18,19)$.

In the present study, we established a cell model of ethanol-induced liver damage to evaluate the hepatoprotective effect of Letinous edodes foot peptides in human L02 hepatocytes. The regulation on aminotransferases, alcohol metabolic enzymes, antioxidation capacities and proinflammatory cytokines was also investigated at the cellular and molecular level.

\section{Materials and methods}

Letinous edodes foot peptides. Letinous edodes foot peptides were obtained from a preliminary experiment (19). The Letinous edodes foot peptides were prepared by an alkali-solution and acid-isolation method, assisted by ultra-high-pressure processing with a pressure of $400 \mathrm{MPa}$ and a processing time of $10 \mathrm{~min}$. After ultrafiltration, three molecular weights of peptides were obtained, of which 0-3 kDa had the highest activity to activate ADH and ALDH by 70.79 and $71.35 \%$, respectively. Therefore, we used Letinous edodes foot peptides with molecular weight of 0-3 $\mathrm{kDa}$ as material in this research to evaluate the protective effect.

Cells and chemicals. Human liver cells (L02) were bought from Shanghai Bo research Biological Technology Co., Ltd. (Shanghai, China). Ethanol, analytical reagent, was obtained from Tianjin Yongda Chemical Reagent Co., Ltd. (Tianjin, China). Alanine aminotransferase (ALT), aspartate aminotransferase (AST), MDA and SOD test kits, and ADH and ALDH ELISA kits were obtained from the Nanjing Institute of Biological Engineering. RPMI-1640 culture medium, $0.25 \%$ pancreatin, penicillin-streptomycin and fetal bovine serum (FBS) were obtained from Gibco; Thermo Fisher Scientific, Inc., (Waltham, MA, USA). PMSF and RIPA cell lysis solutions were obtained from Beyotime Institute of Biotechnology, Haimen, China. The MTT was obtained from Sigma-Aldrich; Merck KGaA (Darmstadt, Germany). DMSO and PBS were procured from Shanghai Jixing Biological Science and Technology Co., Ltd. TRNzol reagent (DP405-02) was obtained from Tian Gen Biochemical Technology Co. Ltd., (Beijing, China). PrimeScript ${ }^{\mathrm{TM}}$ RT reagent kit with gDNA Eraser RR047B, SYBR ${ }^{\circledR}$ Premix Ex Taq ${ }^{\mathrm{TM}}$ II (Tli RNaseH Plus), ROX plus RR82LR, and DL2,000 DNA Marker 3427Q were obtained from Takara Bio, Inc., (Otsu, Japan). Primer synthesis was performed by Invitrogen; Thermo Fisher Scientific, Inc.

Cell culture. L02 cells were cultured in RPMI-1640 medium supplemented with $10 \% \mathrm{FBS}$ and $100 \mathrm{U} / \mathrm{ml}$ penicillin at $37^{\circ} \mathrm{C}$ in a $5 \% \mathrm{CO}_{2}$ humidified environment.

Determination of the damaging concentration of ethanol in the experiment model. L02 cell viability after treatment with ethanol and Letinous edodes foot peptides was measured by the MTT assay. Certain concentration of Letinous edodes foot peptides and ethanol were prepared in a serum-free medium, using Puerariae as control. Puerariae is a famous traditional Chinese medicine with the effect of anti-inebriation. It has been reported that pretreatment with Puerariae extract significantly prolonged the ethanol tolerance duration and shortened intoxication duration, which was accompanied by decreased blood ethanol concentration, elevated ADH and ALDH activities in the liver and decreased ALT and AST activities in the serum (20). Cells were seeded in 96-well plates at a cell density of $5 \times 10^{4}$ cells/well. After treatment with $0,25,50,75,100,200$, $300,400,500$ or $800 \mathrm{mmol} / \mathrm{l}$ ethanol, $10 \mu \mathrm{l}$ of MTT $(5 \mathrm{mg} / \mathrm{ml})$ were added for $4 \mathrm{~h}$. Then, the medium was removed and $150 \mu \mathrm{l}$ of DMSO were added for $10 \mathrm{~min}$. The absorbance was measured at $492 \mathrm{~nm}$.

Determination of the optimal concentration of Letinous edodes foot peptides for protection against ethanol-induced damage. To determine the best concentration of Letinous edodes foot peptides for protection against ethanol-induced damage, $100 \mu \mathrm{l}$ of Letinous edodes foot peptides were added to a 96-well plate prior to ethanol $(200 \mathrm{mmol} / \mathrm{l})$. The final concentrations were $0,6.25,12.5,25,50,75,100,200,400,600$ or $1,200 \mathrm{mg} / 1$, which were proved to have nontoxic effect to the L02 cell in the preliminary experiment (data not shown).

Determination of the addition order of Letinous edodes foot peptides and ethanol. To determine the best addition order of Letinous edodes foot peptides to obtain the best results, we had three experimental groups. In the first group Letinous edodes foot peptides at different concentrations was added to the cells $24 \mathrm{~h}$ prior to ethanol addition. In the second group ethanol was added to the cells $24 \mathrm{~h}$ prior to Letinous edodes foot peptides. In the last group Letinous edodes foot peptides and ethanol were added simultaneously.

Determination of enzyme activity. L02 cells in the logarithmic growth phase were cultured in 96 -well plates $\left(1 \times 10^{6}\right.$ cells/well) for $24 \mathrm{~h}$. The cells were divided into six groups: negative control (no ethanol, no peptides), positive control (ethanol treated), Puerariae group (ethanol treated with pretreatment of $10 \mathrm{mg} / \mathrm{l}$ Puerariae) and peptides groups (ethanol treated with pretreatment of $25,50,100 \mathrm{mg} / \mathrm{l}$ peptides). Six wells were set up for each group. The experiment was performed in an incubator with $5 \% \mathrm{CO}_{2}$ at $37^{\circ} \mathrm{C}$. The interval between adding ethanol and the peptides was 24 , and $24 \mathrm{~h}$ between the last sampling and testing.

After treatment, the cells were rinsed twice with PBS (0.01 mol/l). PMSF ( $1 \mathrm{mmol} / 1,100 \mu \mathrm{l})$ was added to each well and the supernatant was removed after centrifugation (20,000 x g, $10 \mathrm{~min})$. The indexes of oxidative damage in the cell lysis solution, including MDA, SOD, ALT and AST, were examined with the relevant kits.

ELISA assay. Cell treatment and grouping were as described above. Serum-free cell culture medium was added to the negative control group, $200 \mathrm{mmol} / 1$ ethanol solution to the positive control group, and the peptides prior to $200 \mathrm{mmol} / \mathrm{l}$ ethanol solution to the peptides groups for $24 \mathrm{~h}$. After another $24 \mathrm{~h}$, the supernatant was collected to test ADH and ALDH activity. 
Table I. Primer sequences.

Primer name

Primer sequence $\left(5^{\prime}-3^{\prime}\right)$

Product size (bp)

IL-6 upstream primer

IL-6 downstream primer

TNF- $\alpha$ upstream primer

TNF- $\alpha$ downstream primer

AMPK- $\alpha 2$ upstream primer

AMPK- $\alpha 2$ downstream primer

PPAR- $\alpha$ upstream primer

PPAR- $\alpha$ downstream primer

ADH upstream primer

ADH downstream primer

ALDH2 upstream primer

ALDH2 downstream primer

ACTIN upstream primer

ACTIN downstream primer

ATGAGGAGACTTGCCTGGTGAAAAT
TCTGGCTTGTTCCTCACTACT
CTCCTCACCCACACCATCAGCCGCA
ATAGATGGGCTCATACCAGGGCTTG
CGAAGTCAGAGCAAACCGTATG
GAACGCTGAGGTGTTGAGGAA
GATCTGAGAAAGCAAAACTGAAAGC
GCAGTGAAAGATGCGGACCTC
TCCGACCTGGAGCTGAGACA
GGCGACGGCAGGTAGTTCTC
AGTTTGTGGAGCGGAGCGT
CGTGTTGATGTAGCCGAGGA
CTGAAGTACCCCATCGAGCAC
ATAGCACAGCCTGGATAGCAAC

104

IL-, interleukin; TNF, tumor necrosis factor; AMPK, AMP-activated protein kinase; PPAR, peroxisome proliferator-activated receptor; ADH, alcohol dehydrogenase; ALDH2, acetaldehyde dehydrogenase 2.

The relative expression of $m R N A$ measured by reverse transcription-quantitative polymerase chain reaction ( $R T$-qPCR). RT-qPCR was used to detect expressions of target genes. The primers listed in Table I were synthesized by Invitrogen; Thermo Fisher Scientific, Inc. Total RNA was extracted with TRNzol, and cDNA reverse transcription was performed by the PrimeScript RT reagent kit with gDNA Eraser in accordance with the manufacturer's protocol. Amplification was carried out by SYBR Premix Ex Taq II \& reg (Tli RNaseH Plus; Takara Bio, Inc., Otsu, Japan), ROX plus according to the product specifications, using cDNA templates diluted 10 times. Amplification was performed at $95^{\circ} \mathrm{C}$ for $30 \mathrm{sec}$, followed by 45 cycles of $95^{\circ} \mathrm{C}$ for $5 \mathrm{sec}$ and $60^{\circ} \mathrm{C}$ for $40 \mathrm{sec}$. The $2^{-\Delta \Delta \mathrm{Cq}}$ method of quantification was employed (21).

Statistical analysis. All data are presented as means \pm standard error of three experiments. The total variation was estimated by analysis of variance followed by a Duncan multiple comparison test with SPSS $\omega 20.0$ (IBM Corp., Armonk, NY, USA). $\mathrm{P}<0.05$ was considered to indicate a statistically significant difference.

\section{Results}

Establishment of cell model of ethanol-induced damage. As shown in Fig. 1A, at a low concentration $(<50 \mathrm{mmol} / \mathrm{l})$ ethanol did not inhibit the growth of L02 hepatic cells, but it promoted cell proliferation. The reason for this could be that at a low concentration the cells used ethanol as an energy source, resulting in accelerated cell proliferation. As the concentration increased, ethanol inhibited L02 cell proliferation, with an $\mathrm{IC}_{50}$ of $222.8 \pm 14.7 \mathrm{mmol} / \mathrm{l}$. Therefore, the final concentration chosen for the model of ethanol-induced damage was $200 \mathrm{mmol} / \mathrm{l}$.

Next, we incubated L02 cells with different concentrations of Letinous edodes foot peptides for $24 \mathrm{~h}$. Different effects on the proliferation of normal hepatic L02 cells were observed (Table II). When the concentration of Letinous edodes foot peptides was low, the proliferation rate was similar to the cells exposed to ethanol only. However, as the concentration was increased, the L02 cell proliferation rate increased. Furthermore, from 25, 50 and $100 \mathrm{mg} / 1$ the positive effect on proliferation was significant. Thus, we concluded that the peptides could promote the growth of normal human liver L02 cells of ethanol-induced damaged.

The MTT assay was used to examine the cell viability of L02 cells treated with different concentrations of Letinous edodes foot peptides and $200 \mathrm{mmol} / \mathrm{l}$ ethanol, which were added in three different sequences: Ethanol first, both substances simultaneously, or peptides first (Fig. 1B). Similar to the $10 \mathrm{mg} / \mathrm{l}$ Puerariae control, in the cells in which the Letinous edodes foot peptides of $25,100 \mathrm{mg} / \mathrm{l}$ was added $24 \mathrm{~h}$ before the ethanol, the cell viability tended to be extremely significantly higher than that of the other two groups $(\mathrm{P}<0.01)$. In a comprehensive way, we added the Letinous edodes foot peptides prior to the ethanol treatment in the following experiments.

Measurement of aminotransferases' activity. As shown in Fig. 2A, the AST enzyme activity in the positive control group significantly increased compared with that in the negative control group. However, a significant decrease was observed in the groups pretreated with the Letinous edodes foot peptides. With the increase in the Letinous edodes foot peptides concentration, AST activity decreased gradually, though the Puerariae group showed an even lower AST activity. The results suggest that Letinous edodes foot peptides can effectively suppress the liver cell damage-induced elevation in AST activity. Compared with the negative control, the ALT activity in the positive control group was significantly enhanced (Fig. 2B). Letinous edodes foot peptides at $25-100 \mathrm{mg} / 1$ prominently suppressed the increase in ALT enzyme activity in L02 liver cells induced by 

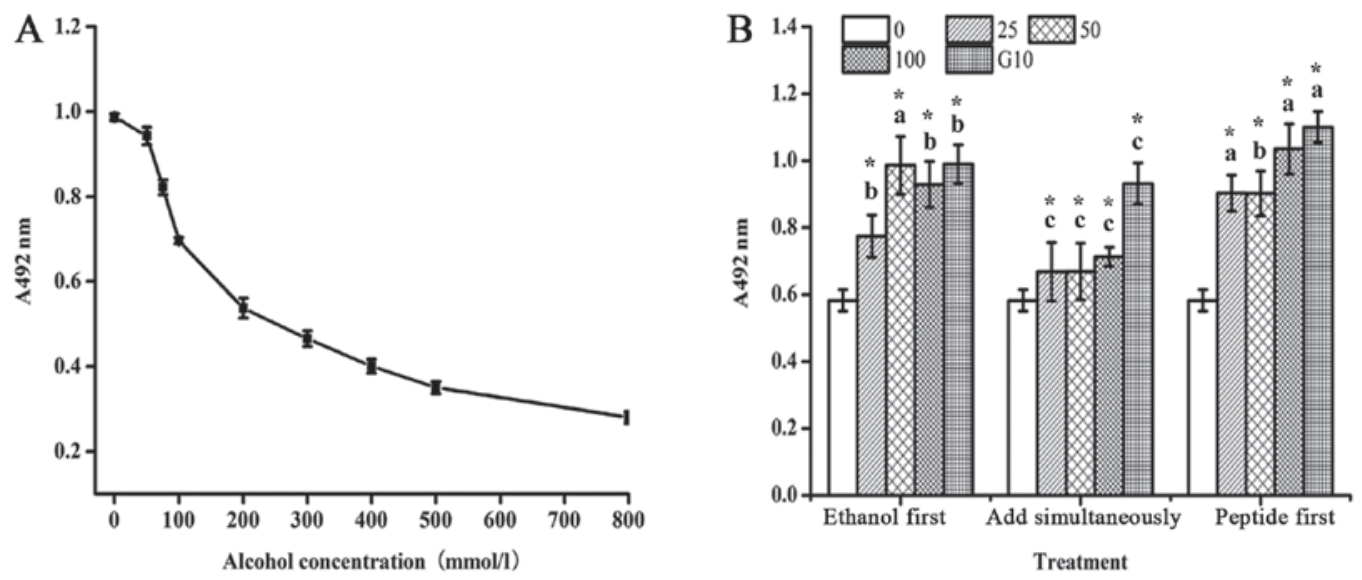

Figure 1. Establishment of ethanol-induced cell model. (A) Associations between ethanol concentration and ethanol-induced damage. (B) Effect of the treatment order of Letinous edodes foot peptides and ethanol on L02 cell proliferation. "P<0.01 vs. control ( 0 mmol/l) within the same treatment group; ${ }^{\mathrm{a}-\mathrm{c}} \mathrm{P}<0.01$, comparisons between the different treatment groups of the same concentration.

ethanol. Thus, Letinous edodes foot peptides have an obvious protective effect on ethanol-induced damage in L02 liver cells.

Measurement of antioxidant indexes. As shown in Fig. 3A, compared with the positive control, the Letinous edodes foot peptides significantly decreased the MDA content in liver cells injured by ethanol in a dose-dependent manner. Furthermore, $100 \mathrm{mg} / \mathrm{l}$ peptides significantly decreased the MDA level compared to that observed in the Puerariae group. These results indicate that the Letinous edodes foot peptides can decrease the content of MDA in ethanol-damaged liver cells.

Next, we examined the effect of Letinous edodes foot peptides on SOD activity. Compared with the negative control, ethanol significantly reduced SOD activity (Fig. 3B). In contrast, Letinous edodes foot peptides $(25-100 \mathrm{mg} / \mathrm{l})$ significantly improved the SOD activity in ethanol-damaged L02 cells, and the same effect was observed with $10 \mathrm{mg} / \mathrm{l}$ Puerariae.

Measurement of dehydrogenases by ELISA and RT-qPCR. As shown in Fig. 4A and B, the amount of ADH secretion increased after ethanol exposure for $24 \mathrm{~h}$ compared with the negative control. This increase was slightly suppressed by pretreating with Letinous edodes foot peptides or Puerariae. ADH secretion in the Puerariae group was slightly higher than that in the $50 \mathrm{mg} / 1$ Letinous edodes foot peptides group, but lower than that in the $25 \mathrm{mg} / 1$ group. Ethanol also increased ALDH secretion compared with the negative control; however, Letinous edodes foot peptides reversed this increase. The amount of ALDH secretion was the lowest in the $25 \mathrm{mg} / \mathrm{l}$ peptides group and the highest in the Puerariae group.

As displayed in Fig. 4C and D, compared with the negative control, the upregulation of ADH and ALDH2 mRNA stimulated by ethanol in the positive control group was significantly suppressed. This effect was reversed by pretreatment with Puerariae and Letinous edodes foot peptides in a dose-dependent manner. The ADH and ALDH2 mRNA relative expression was in the following order: Negative control $>$ Puerariae group $(10 \mathrm{mg} / \mathrm{l})>$ peptides group $(100 \mathrm{mg} / \mathrm{l})>$ peptides group $(50 \mathrm{mg} / \mathrm{l})>$ peptides group ( $25 \mathrm{mg} / \mathrm{l})>$ positive control, and the positive control group showed significant differences compared with the other groups.

Expression of proinflammatory cytokines. As shown in Fig. 5, compared with the negative control, the expression of IL- 6 and TNF- $\alpha$ mRNA in the positive control group was significantly higher. This upregulation was significantly suppressed by treatment with Letinous edodes foot peptides in a dose-dependent manner, even lower with $100 \mathrm{mg} / \mathrm{l}$ of peptides group compared with Puerariae group. These results indicate that Letinous edodes foot peptides can relieve liver injury.

Expression of metabolic regulation factors. As shown in Fig. 6 , compared with the negative control, the relative expression of AMPK- $\alpha 2$ and PPAR- $\alpha$ mRNA in the positive control group was lower. This effect was reversed by Letinous edodes foot peptides and Puerariae. The influence of the low concentration $(25 \mathrm{mg} / \mathrm{l})$ of Letinous edodes foot peptides on PPAR- $\alpha$ mRNA relative expression was not significant, but that of the other concentration groups $(50,100 \mathrm{mg} / \mathrm{l})$ was significant compared with the positive control group. PPAR- $\alpha$ expression in the Puerariae group showed no difference compared with the positive control group.

\section{Discussion}

SOD is a scavenger of superoxide anion radicals, transforming them into harmless oxygen and water molecules, thus protecting cells from free radical damage. Acute ethanol excess can cause a decrease in SOD activity and accumulation of a large amount of free radicals, which raise the lipid peroxidation reaction with polyunsaturated fatty acids in biological membranes, producing peroxide lipids afterwards. This kind of substance, with poor stability, will continue to produce MDA and other substances $(22,23)$. MDA can cause serious liver cell damage which will change the cell membrane fluidity and permeability. SOD and MDA are regularly measured together, as the level of SOD activity is proportional to the free radical scavenging ability of the organism, and the MDA content in the 
Table II. Effect of Letinous edodes foot peptides on the proliferation of ethanol-damaged L02 cells.

$\mathrm{A}_{492 \mathrm{~nm}}$

Reagent and concentration

$\begin{array}{lll}\mathrm{A}_{492 \mathrm{~nm}} & \\ \text { Repeat } 1 \quad \text { Repeat } 3\end{array}$

Average

No ethanol, no peptides

0

0.99

1.077

0.987

$1.018 \pm 0.051$

Ethanol (mmol/l)

200

0.39

0.382

0.406

$0.393 \pm 0.012^{\mathrm{a}}$

Peptides (mg/l)

\begin{tabular}{lllll}
6.25 & 0.366 & 0.43 & 0.426 & $0.407 \pm 0.036^{\mathrm{a}}$ \\
12.5 & 0.433 & 0.433 & 0.354 & $0.407 \pm 0.045^{\mathrm{a}}$ \\
25 & 0.48 & 0.446 & 0.428 & $0.452 \pm 0.026^{\mathrm{b}}$ \\
50 & 0.465 & 0.524 & 0.484 & $0.491 \pm 0.030^{\mathrm{b}}$ \\
75 & 0.474 & 0.483 & 0.528 & $0.495 \pm 0.029^{\mathrm{b}}$ \\
100 & 0.543 & 0.496 & 0.552 & $0.530 \pm 0.030^{\mathrm{b}}$ \\
200 & 0.592 & 0.498 & 0.547 & $0.546 \pm 0.047^{\mathrm{b}}$ \\
400 & 0.644 & 0.561 & 0.562 & $0.589 \pm 0.048^{\mathrm{b}}$ \\
600 & 0.59 & 0.625 & 0.607 & $0.607 \pm 0.018^{\mathrm{b}}$ \\
1,200 & 0.71 & 0.63 & 0.744 & $0.695 \pm 0.058^{\mathrm{b}}$ \\
Puerariae (mg/l) & & & & $0.662 \pm 0.034^{\mathrm{b}}$ \\
10 & 0.665 & 0.694 & 0.626 & $0.967 \pm 0.042^{\mathrm{b}}$ \\
25 & 1.015 & 0.938 & 0.947 & \\
\hline
\end{tabular}

${ }^{\mathrm{a} P}<0.05$ and ${ }^{\mathrm{b}} \mathrm{P}<0.01$ vs. No ethanol, no peptides.
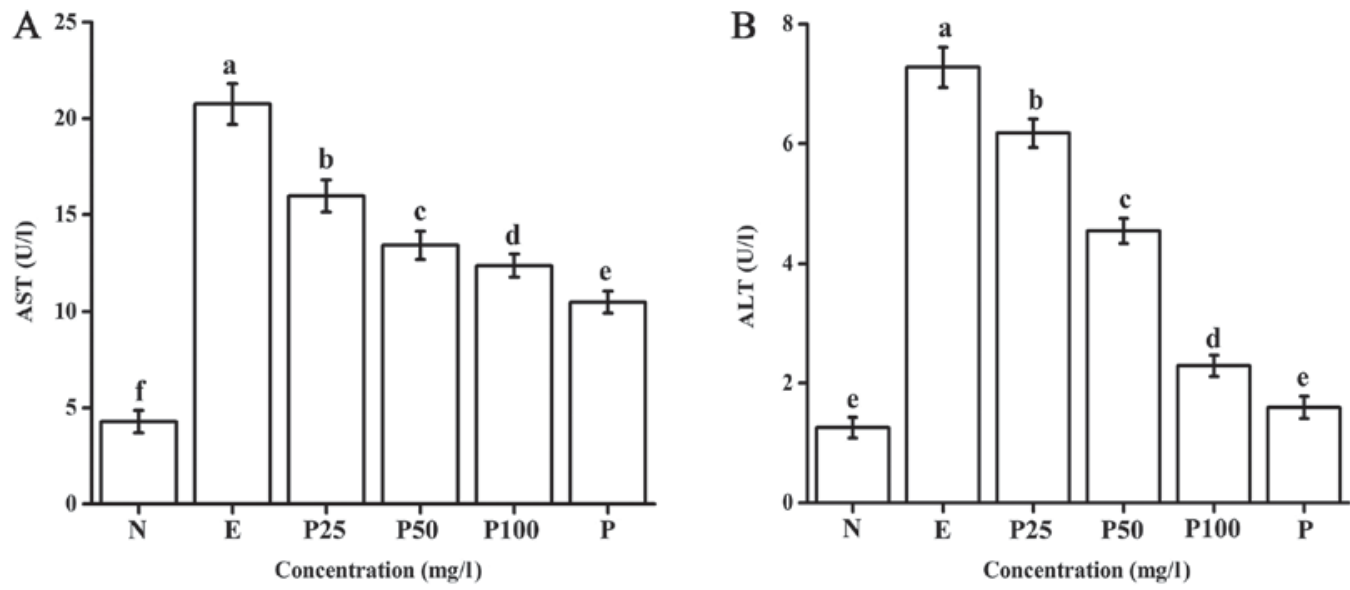

Figure 2. Effect of Letinous edodes foot peptides on (A) AST and (B) ALT activity. Samples were divided into the following groups: N, negative control (no ethanol, no peptides), E, positive control (ethanol treated), P25, peptides group (ethanol treated with pretreatment of $25 \mathrm{mg} / 1$ peptides), P50, peptides group (ethanol treated with pretreatment of $50 \mathrm{mg} / 1$ peptides), P100, peptides group (ethanol treated with pretreatment of $100 \mathrm{mg} / 1$ peptides), P, Puerariae group (ethanol treated with pretreatment of $10 \mathrm{mg} / 1$ Puerariae). ${ }^{\text {a-f }} \mathrm{P}<0.05$. AST, aspartate aminotransferase; ALT, alanine aminotransferase.

cells reflects the degree of free radical attack. Combining SOD with MDA analysis is helpful in studying the mechanism of biological activity. Zhang et al (24) have reported that bamboo leaf flavonoids significantly increased the SOD activity and reduced the MDA content against ethanol-induced liver injury. She et al (25) proved that corn peptides protected liver cells from oxidative damage induced by ethanol metabolism. Hong et al (26) confirmed that fermented Adlay increased the activities of antioxidant enzymes such as SOD in the liver. The results of this study showed that Letinous edodes foot peptides significantly improved the SOD activity in the ethanol-induced L02 cell model and reduced the MDA content, demonstrating its hepatoprotective effect.

Under normal circumstances, the concentrations of AST and ALT in liver cells are 1,000-5,000 times higher than in the serum. If the liver tissue is injured, liver cell swelling and necrosis, or increased membrane permeability of liver cells will occur, followed by secretion of transaminase into 

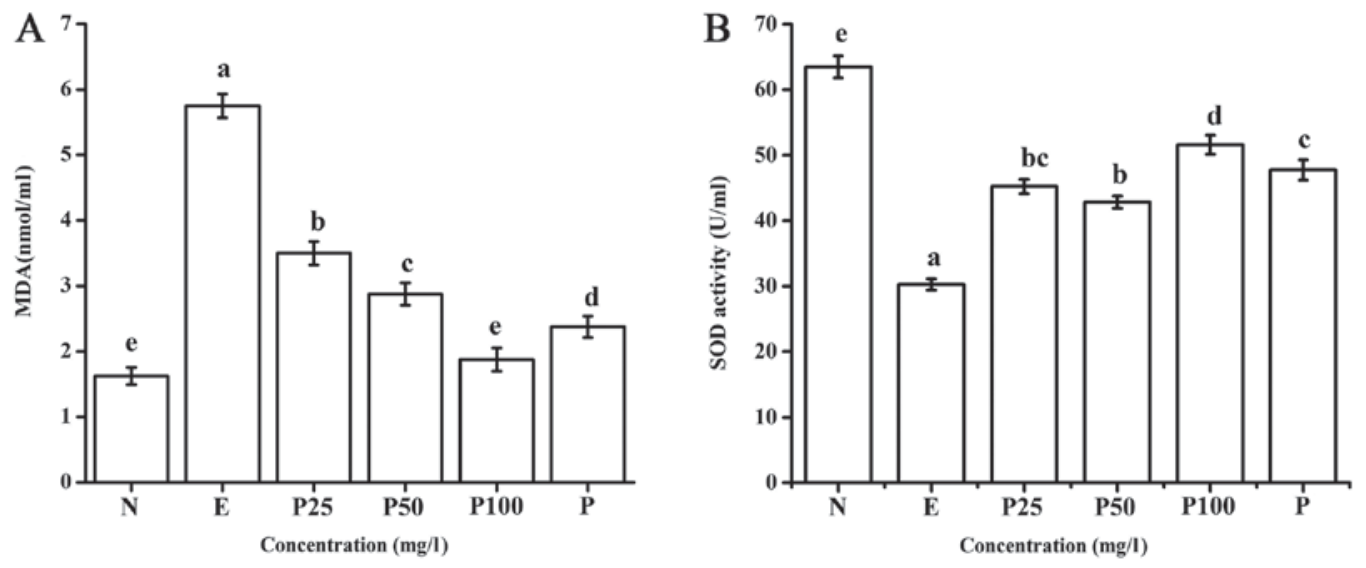

Figure 3. Effect of Letinous edodes foot peptides on the (A) MDA and (B) SOD content. ${ }^{\mathrm{a}-\mathrm{e}} \mathrm{P}<0.05$. SOD, superoxide dismutase; MDA, malondialdehyde; N, negative control (no ethanol, no peptides), E, positive control (ethanol treated), P25, peptides group (ethanol treated with pretreatment of $25 \mathrm{mg} / 1 \mathrm{peptides),}$ P50, peptides group (ethanol treated with pretreatment of $50 \mathrm{mg} / \mathrm{l}$ peptides), $\mathrm{P} 100$, peptides group (ethanol treated with pretreatment of $100 \mathrm{mg} / \mathrm{l}$ peptides), $\mathrm{P}$, Puerariae group (ethanol treated with pretreatment of $10 \mathrm{mg} / 1$ Puerariae).
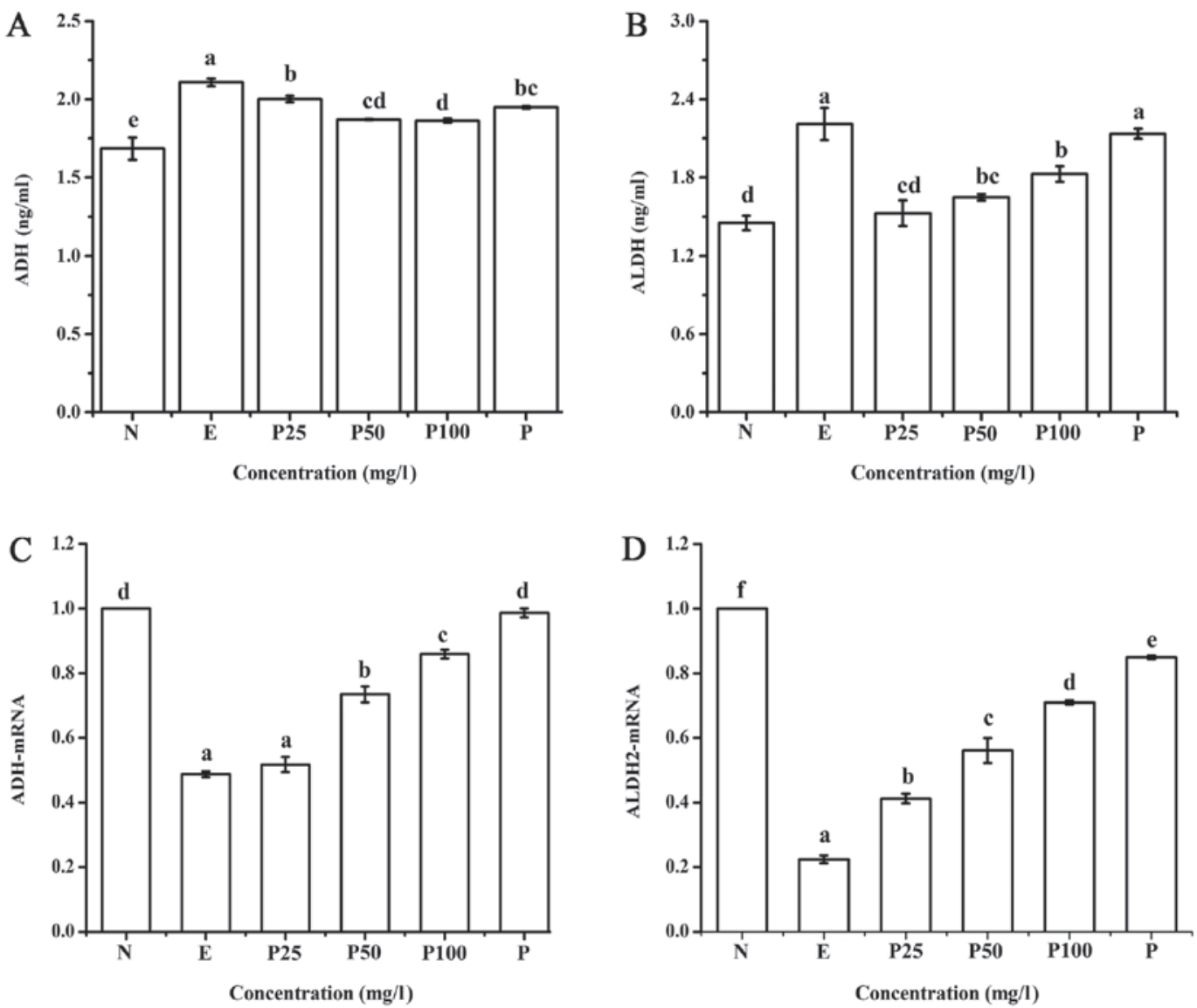

Figure 4. Content of the dehydrogenases (A) ADH and (B) ALDH was measured by ELISA assay. The mRNA expression of (C) ADH and (D) ALDH2 was measured by reverse transcription-quantitative polymerase chain reaction. ${ }^{\mathrm{a}-\mathrm{P}} \mathrm{P}<0.05$. ADH, alcohol dehydrogenase; ALDH, acetaldehyde dehydrogenase; $\mathrm{N}$, negative control (no ethanol, no peptides), E, positive control (ethanol treated), P25, peptides group (ethanol treated with pretreatment of $25 \mathrm{mg} / \mathrm{l}$ peptides), P50, peptides group (ethanol treated with pretreatment of $50 \mathrm{mg} / \mathrm{l}$ peptides), $\mathrm{P} 100$, peptides group (ethanol treated with pretreatment of $100 \mathrm{mg} / \mathrm{l}$ peptides), $\mathrm{P}$, Puerariae group (ethanol treated with pretreatment of $10 \mathrm{mg} / 1$ Puerariae).

the blood, contributing to the increase in serum transaminase activity. Because aminotransferase activity in the liver is much higher than that in the blood under normal conditions, its change in serum is a specific marker used to assess hepatocellular damage in clinic $(22,27)$. Zhang et al (3) investigated the protective effect of anthocyanins from purple sweet potato on acute carbon tetrachloride-induced liver injury in mice, which showed that the anthocyanins could significantly reduce the carbon tetrachloride-induced ALT and AST activity, demonstrating its protective effect. The results of this study showed that the Letinous edodes foot peptides reduced the damage index ALT and AST enzyme activity in 

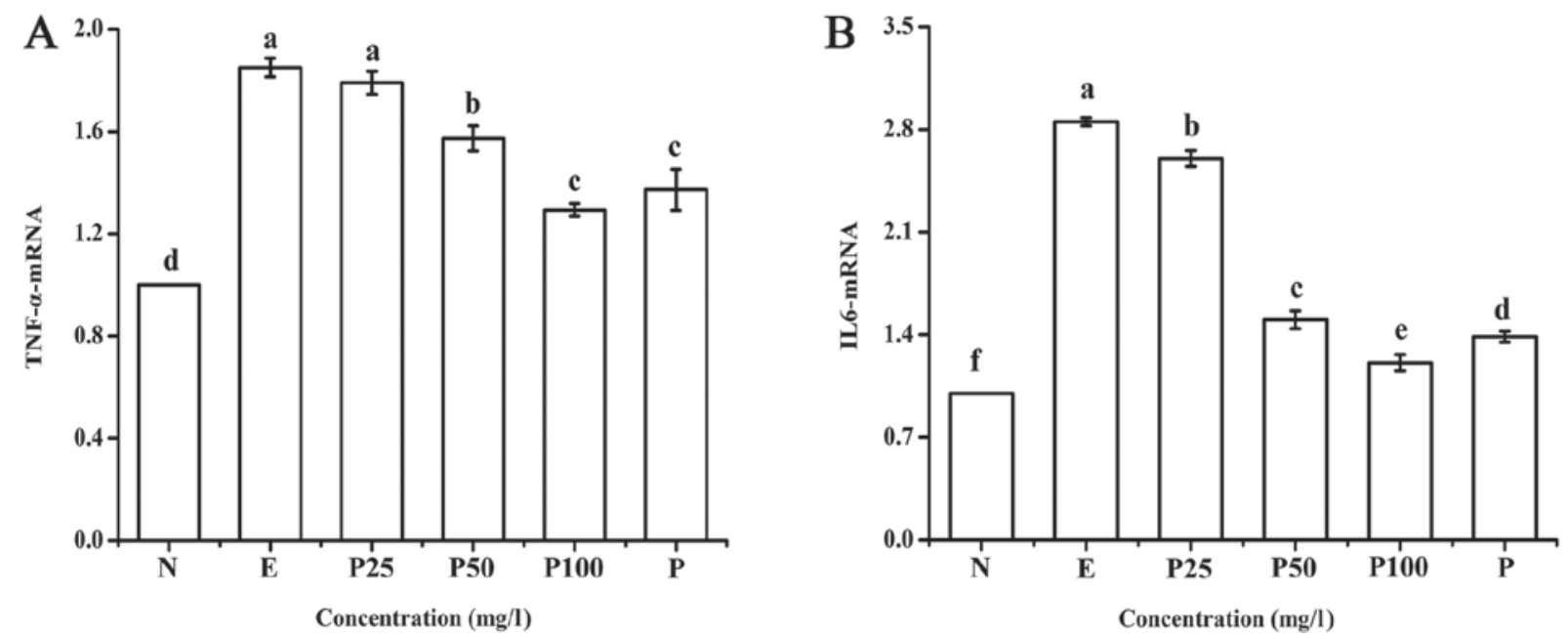

Figure 5. Effect of Letinous edodes foot peptides on the mRNA expression of (A) TNF- $\alpha$ and (B) IL-6. ${ }^{\text {a-f }} \mathrm{P}<0.05$. IL, interleukin; TNF, tumor necrosis factor; $\mathrm{N}$, negative control (no ethanol, no peptides), E, positive control (ethanol treated), P25, peptides group (ethanol treated with pretreatment of $25 \mathrm{mg} / \mathrm{l}$ peptides), P50, peptides group (ethanol treated with pretreatment of $50 \mathrm{mg} / \mathrm{l}$ peptides), P100, peptides group (ethanol treated with pretreatment of $100 \mathrm{mg} / \mathrm{l}$ peptides), $\mathrm{P}$, Puerariae group (ethanol treated with pretreatment of $10 \mathrm{mg} / 1$ Puerariae).
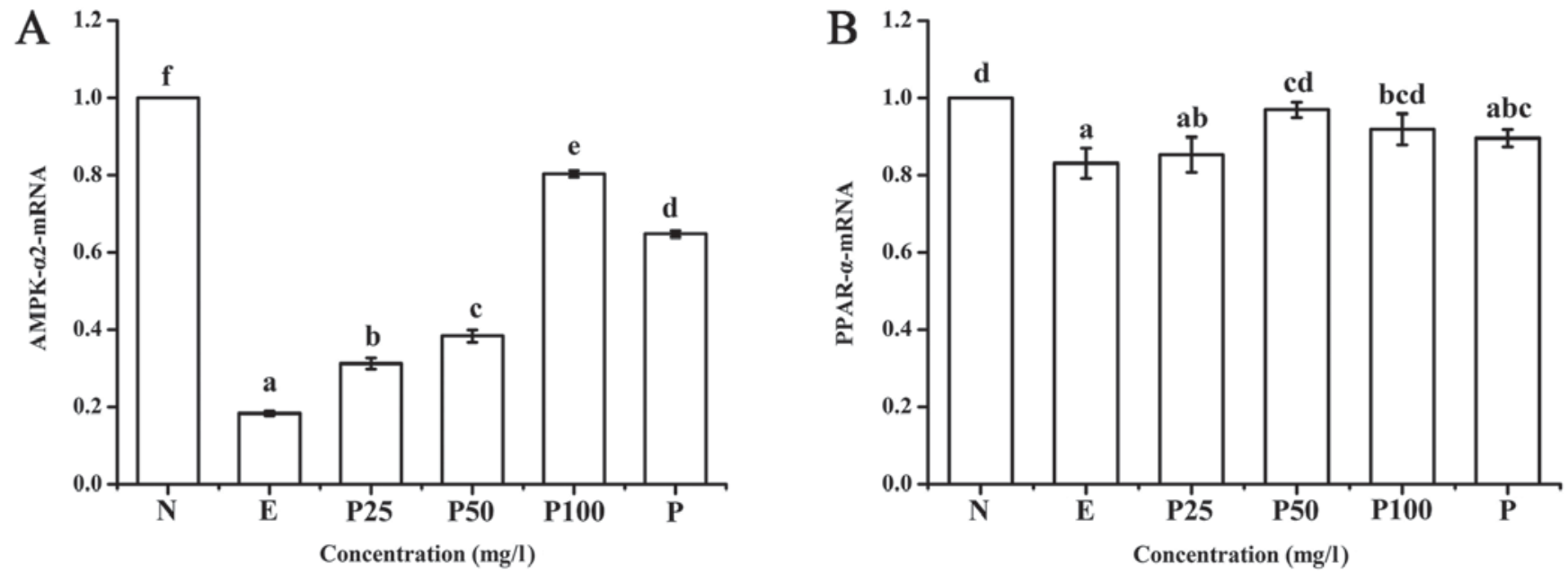

Figure 6. Effect of Letinous edodes foot peptides on the mRNA expression of (A) AMPK- $\alpha 2$ and (B) PPAR- $\alpha .{ }^{\mathrm{a}-\mathrm{P}} \mathrm{P}<0.05$. AMPK, AMP-activated protein kinase; PPAR, peroxisome proliferator-activated receptor; N, negative control (no ethanol, no peptides), E, positive control (ethanol treated), P25, peptides group (ethanol treated with pretreatment of $25 \mathrm{mg} / \mathrm{l}$ peptides), P50, peptides group (ethanol treated with pretreatment of $50 \mathrm{mg} / \mathrm{l}$ peptides), P100, peptides group (ethanol treated with pretreatment of $100 \mathrm{mg} / \mathrm{l}$ peptides), P, Puerariae group (ethanol treated with pretreatment of $10 \mathrm{mg} / 1$ Puerariae).

ethanol-induced liver cells, confirming its protective effect on the liver.

It has been shown that when the body was stimulated by ethanol, the liver cells produced ADH to metabolize ethanol, which was oxidized to acetaldehyde, and then oxidized to acetic acid by ALDH. Therefore, the release of ADH and ALDH gradually increases with the increase in ethanol metabolism. ADH is a metal enzyme with zinc atoms, which plays a major role in ethanol metabolism. It is mainly expressed in the liver, intestines and stomach; however, in the liver it is mainly located in the cell fluid. The change in ADH activity has two sides. If the activity increases, the oxidation of ethanol to acetaldehyde is accelerated, providing the conditions for further metabolism of non-toxic products. However, if the activity change is not timely for the oxidation of acetaldehyde to acetic acid, the damage to the liver cells will be more serious compared with ethanol. If ADH activity is inhibited, the ethanol hazard for the body itself will increase $(28,29)$. ALDH is also an important enzyme in ethanol metabolism, as it can transform toxic acetaldehyde associated with alcoholic liver injury into acetic acid, which is a nontoxic metabolic product. If the activities of ADH or ALDH are weakened, the ethanol itself or the intermediate metabolite, acetaldehyde, will produce toxic effects, which may lead to liver cell mitochondria damage, affecting the energy metabolism of liver cells, and inducing cell apoptosis and necrosis, thus aggravating liver injury $(30,31)$. At present, many studies have indicated that apoptosis is involved in the occurrence of ALD, which is an important part of the pathogenesis of ALD (32). The current study showed that the Letinous edodes foot peptides increased the mRNA expression of ADH and ALDH, which 
was obviously reduced by ethanol, confirming its protective effect on the liver.

TNF- $\alpha$, the most important cytokine in alcoholic liver injury, is secreted by intrahepatic Kupffer cells, and its level in vivo increases when ethanol activates the extracellular receptor-activated kinase. Liver injury induced by ethanol has also been associated with the level of AMPK and PPAR- $\alpha$. Besides, TNF- $\alpha$ promotes the release of other inflammatory cytokines (such as IL-1 and IL-6), which promote liver cell damage caused by inflammation, and even cause liver cell death. Ethanol can influence inflammatory reactions by TNF- $\alpha$, AMPK and PPAR- $\alpha$, leading to cell apoptosis and necrosis (33-36). Vidyashankar et al (37) have reported that ethanol in metabolic processes will consume coenzyme Q10 in the liver, which can enhance TNF- $\alpha$ secretion, thus producing substances harmful to HepG2 cells. Shearn et al (38) have reported that AMPK expression significantly decreased after ethanol intake in mice with a high-fat diet. Studies in mouse and rat cultured liver cells in vitro have demonstrated that ethanol suppressed the expression of PPAR- $\alpha$ and the binding of PPAR- $\alpha / R X R$ to DNA, thus promoting liver steatosis, inflammation, necrosis and fibrosis (39). Park et al (34) found that Schisandra chinensis has the ability to prevent ethanol-induced fatty liver by a significant increase in AMPK and PPAR- $\alpha$ expression in hepatic tissue of alcoholic rats. Our research revealed that the Letinous edodes foot peptides have a role in protecting the liver by inhibiting the mRNA expression of IL-6 and TNF- $\alpha$ and enhanced the mRNA expression of the metabolic regulation factors AMPK- $\alpha 2$ and PPAR- $\alpha$, demonstrating the protective effect of Letinous edodes foot peptides.

In conclusion, this research, using a cell model in vitro, demonstrated the effect of ethanol-induced damage on cell proliferation and the protection effect on Letinous edodes foot peptides using the MTT assay. Furthermore, we studied the protective effect of Letinous edodes foot peptides on ethanol-damaged liver cells at the cellular and molecular levels by measuring the mRNA expression of proinflammatory factors, metabolic regulation factors and sober enzyme factors using ELISA and RT-qPCR. According to our results, Letinous edodes foot peptides significantly improved the SOD activity and the mRNA expression of ADH and ALDH, which were obviously reduced by ethanol. It also reduced the intracellular MDA content, and the AST and ALT activity. The ethanol-stimulated activation of the proinflammatory cytokines, IL- 6 and TNF- $\alpha$, in L02 cells was significantly blocked, and the metabolic regulation factors, AMPK- $\alpha 2$ and PPAR- $\alpha$, and the sober enzyme factors, ADH and ALDH2, were induced by Letinous edodes foot peptides. Hence, we concluded that Letinous edodes foot peptides have a protective effect on normal human liver L02 cells, preliminarily determined that the peptides have the effect of sobering up. More deep study of the pathway factors including protein expression, as well as the exact extent of the effect in human should be strengthened in further researches. Whether the peptides can be used to treat ethanol-induced liver injury needs later animal and clinical trials.

\section{Acknowledgements}

Not applicable.

\section{Funding}

The present study was supported by grants from the National Natural Science Foundation of China (grant no. 31671963) and the Major State Research Development Program of China (grant no. 2016YFD0400604).

\section{Availability of data and materials}

The datasets used and/or analyzed during the current study are available from the corresponding author on reasonable request.

\section{Authors' contributions}

LM, DFR and JL conceived, designed and supervised the research. LM and CYH performed the experiments. $\mathrm{CYH}$, $\mathrm{XYZ}$ and CQQ conducted the data analysis. LM and JL wrote the manuscript. All authors have read and approved the final manuscript.

\section{Ethics approval and consent to participate}

Not applicable.

\section{Consent for publication}

Not applicable.

\section{Competing interests}

The authors declare that they have no competing interests.

\section{References}

1. Palipoch S, Koomhin P, Punsawad C, Na-Ek P, Sattayakhom A and Suwannalert P: Heme oxygenase-1 alleviates alcoholic liver steatosis: Histopathological study. J Toxicol Pathol 29: 7-15, 2016

2. Coombes JD and Syn WK: Chapter 5-pathogenic mechanisms in alcoholic liver disease (ALD): Emerging role of osteopontin. Mol Asp Alcohol Nut: 63-70, 2016.

3. Zhang M, Pan LJ, Jiang ST and Mo YW: Protective effects of anthocyanins from purple sweet potato on acute carbon tetrachloride-induced oxidative hepatotoxicity fibrosis in mice. Food Agr Immunol 27: 157-170, 2016.

4. DeNucci SM, Tong M, Longato L, Lawton M, Setshedi M, Carlson RI, Wands JR and de la Monte SM: Rat strain differences in susceptibility to alcohol-induced chronic liver injury and hepatic insulin resistance. Gastroent Res Pract 2010: 16, 2010.

5. Liu WH, Liu TC and Yin MC: Beneficial effects of histidine and carnosine on ethanol-induced chronic liver injury. Food Chem Toxicol 46: 1503-1509, 2008.

6. Miller AM, Wang H, Park O, Noriguchi N, Lafdil F, Mukhopadhyay P, Moh A, Fu XY, Kunos G, Pacher P and Gao B: Anti-inflammatory and anti-apoptotic roles of endothelial cell STAT3 in alcoholic liver injury. Alcoholism Clin Exp Res 34: 719-725, 2010

7. Larter CZ, Yeh MM, Van Rooyen DM, Brooling J, Ghatora K and Farrel GC: Peroxisome proliferator-activated receptor- $\alpha$ agonist, Wy 14,643, improves metabolic indices, steatosis and ballooning in diabetic mice with non-alcoholic steatohepatitis. J Gastroenterol Hepatol 27: 341-350, 2012.

8. Gebrelibanos M, Megersa N and Taddesse AM: Levels of essential and non-essential metals in edible mushrooms cultivated in Haramaya, Ethiopia. Int J Food Contaminat 3: 2, 2016.

9. Zhao YM, Wang J, Wu ZG, Yang JM, Li W and Shen LX: Extraction, purification and anti-proliferative activities of polysaccharides from Lentinus edodes. Int J Biol Macromol 93: 136-144, 2016. 
10. Dubost NJ, Ou B and Beelman RB: Quantification of polyphenols and ergothioneine in cultivated mushrooms and correlation to total antioxidant capacity. Food Chem 105: 727-735, 2007.

11. Finimundy TC, Dillon AJP, Henriques JAP and Ely MR: A review on general nutritional compounds and pharmacologica properties of the Lentinula edodes mushroom. Food Nut Sci 5: 1095-1105, 2014

12. Bak WC, Park JH, Park YA and Ka KH: Determination of glucan contents in the fruiting bodies and mycelia of Lentinula edodes cultivars. Mycobiology 42: 301-304, 2014.

13. Wang L, Wang C, Gao X, Xu N, Lin L, Zhao H, Jia S and Jia L: Purification, characterization and anti-aging capacity of mycelia zinc polysaccharide by Lentinus edodes SD-08. BMC Complement Altern Med 15: 111, 2015.

14. Grotto D, Bueno DC, Ramos GK, da Costa SR, Spim SR and Gerenutti M: Assessment of the safety of the Shiitake culinary-medicinal mushroom, Lentinus edodes (agaricomycetes), in rats: Biochemical, hematological, and antioxidative parameters. Int J Med Mushrooms 18: 861-870, 2016

15. Palacios I, Lozano M, Moro C, D'Arrigo M, Rostagno MA, Martínez JA, García-Lafuente A, Guillamón E and Villares A: Antioxidant properties of phenolic compounds occurring in edible mushrooms. Food Chem 128: 674-678, 2011.

16. Thetsrimuang C, Khammuang S and Sarnthima R: Antioxidant activity of crude polysaccharides from edible fresh and dry mushroom fruiting bodies of Lentinus sp. Strain RJ-2. Int J Pharmacol 7: 58-65, 2011.

17. He JZ, Ru QM, Dong DD and Sun PL: Chemical characteristics and antioxidant properties of crude water soluble polysaccharides from four common edible mushrooms. Molecules 17: 4373-4387, 2012.

18. Cheng Z, Yang YD, Kuang QR, Sun BJ, Ren DF and Lu J: Extraction optimization of Letinous edodes peptide and its antioxidant antialcoholism activity in vitro. J Chin Inst Food Sci Tech 15: 93-102, 2015.

19. Zhao RJ, Huo CY, Qian Y, Ren DF and Lu J: Ultra-high-pressure processing improves proteolysis and release of bioactive peptides with activation activities on alcohol metabolic enzymes in vitro from mushroom foot protein. Food Chem 231: 25-32, 2017.

20. Chen X, Cai F, Guo S, Ding F, He Y, Wu J and Liu C: Protective effect of Flos Puerariae extract following acute ethanol intoxication in mice. Alcohol Clin Exp Res 38: 1839-1846, 2014.

21. Livak KJ and Schmittgen TD: Analysis of relative gene expression data using real-time quantitative PCR and the 2(-Delta Delta C(T)) method. Methods 25: 402-408, 2001.

22. Zhang L, Zhao Q, Wang L, Zhao M and Zhao B: Protective effect of polysaccharide from maca (Lepidium meyenii) on Hep-G2 cells and alcoholic liver oxidative injury in mice. Int $\mathbf{J}$ Biol Macromol 99: 63-70, 2017.

23. Zhao L, Jiang Y, Ni Y, Zhang T, Duan C, Huang C, Zhao Y, Gao L and Li S: Protective effects of Lactobacillus plantarum C88 on chronic ethanol-induced liver injury in mice. J Funct Foods 35: 97-104, 2017.

24. Zhang S, Chen J, Sun AD and Zhao LY: Protective effects and antioxidant mechanism of bamboo leaf flavonoids on hepatocytes injured by $\mathrm{CCl}_{4}$. Food Agr Immunol 25: 386-396, 2014.

25. She XX, Wang F, Ma J, Chen X, Ren DF and Lu J: In vitro antioxidant and protective effects of corn peptides on ethanol-induced damage in HepG2 cells. Food Agr Immunol 27: 99-110, 2016.
26. Hong IH, Choi JY, Kim AY, Lee EM, Kim JH, Park JH, Choi SW and Jeong KS: Anti-rheumatoid arthritic effect of fermented Adlay and Achyranthes japonica Nakai on collagen-induced arthritis in mice. Food Agr Immunol 28: 14-26, 2017.

27. Zhou T, Zhang YJ, Xu DP, Wang F, Zhou Y, Zheng J, Li Y, Zhang JJ and Li HB: Protective effects of lemon juice on alcohol-induced liver injury in mice. Biomed Res Int 2017: 7463571, 2017.

28. Zhong Z, Ye S, Xiong Y, Wu L, Zhang M, Fan X, Li L, Fu Z, Wang $\mathrm{H}$, Chen M, et al: Decreased expression of mitochondrial aldehyde dehydrogenase-2 induces liver injury via activation of the mitogen-activated protein kinase pathway. Transpl Int 29: 98-107, 2016

29. Deng S, Yang X, Lassus H, Liang S, Kaur S, Ye Q, Li C, Wang LP, Roby KF, Orsulic S, et al: Distinct expression levels and patterns of stem cell marker, aldehyde dehydrogenase isoform 1 (ALDH1), in human epithelial cancers. PLoS One 5: e10277, 2010.

30. Lee WH and Kim SG: AMPK-dependent metabolic regulation by PPAR agonists. PPAR Res 2010: pii: 549101, 2010.

31. Pyper SR, Viswakarma N, Yu S and Reddy JK: PPARalpha: energy combustion, hypolipidemia, inflammation and cancer. Nucl Recept Signal 8: e002, 2010.

32. Smathers RL, Chiang DJ, McMullen MR, Feldstein AE, Roychowdhury S and Nagy LE: Soluble IgM links apoptosis to complement activation in early alcoholic liver disease in mice. Mol Immunol 72: 9-18, 2016.

33. Li W, Qu XN, Han Y, Zheng SW, Wang J and Wang YP: Ameliorative effects of 5-hydroxymethyl-2-furfural (5-HMF) from Schisandra chinensis on alcoholic liver oxidative injury in mice. Int J Mol Sci 16: 2446-2457, 2015.

34. Park HJ, Lee SJ, Song Y, Jang SH, Ko YG, Kang SN, Chung BY, Kim HD, Kim GS and Cho GH: Schisandra chinensis prevents alcohol-induced fatty liver disease in rats. J Med Food 17: 103-110, 2014.

35. Ronis MJ, Korourian S, Blackburn ML, Badeaux J and Badger TM: The role of ethanol metabolism in development of ethanolic steatohepatitis in the rat. Alcohol 44: 157-169, 2010

36. Sousa BCD, Miguel CB, Rodrigues WF, Machado JR, Silva MVD, Costa TAD, Lazo-Chica JE, Degasperi TDP, Sales-Campos H, Bucek EU and Oliverira CGF: Effects of short-term consumption of Morinda citrifolia (Noni) fruit juice on mice intestine, liver and kidney immune modulation. Food Agr Immunol 28: 1-15, 2017.

37. Vidyashankar S, Nandakumar KS and Patki PS: Alcohol depletes coenzyme-Q(10) associated with increased TNF-alpha secretion to induce cytotoxicity in HepG2 cells. Toxicology 302: 34-39, 2012.

38. Shearn CT, Smathers RL, Jiang H, Orlicky DJ, Maclean KN and Petersen DR: Increased dietary fat contributes to dysregulation of the LKB1/AMPK pathway and increased damage in a mouse model of early-stage ethanol-mediated steatosis. J Nutr Biochem 24: 1436-1445, 2013.

39. Wang F, Liu JC, Zhou RJ, Zhao X, Liu M, Ye H and Xie ML: Apigenin protects against alcohol-induced liver injury in mice by regulating hepatic CYP2E1-mediated oxidative stress and PPAR $\alpha$-mediated lipogenic gene expression. Chem Biol Interact 275: 171-177, 2017. 